DOI: $10.1590 / 1089-6891 v 20 e-50604$

MEDICINA VETERINÁRIA

\title{
VALORES HEMATOLÓGICOS DE LOBINHOS (Cerdocyon thous) DO PANTANAL, MATO GROSSO DO SUL, BRASIL NATURALMENTE INFECTADOS E NÃO INFECTADOS POR Trypanosoma cruzi e T. evansi
}

\author{
HEMATOLOGICAL VALUES OF CRAB EATING FOXES (Cerdocyon thous) \\ FROM PANTANAL, MATO GROSSO DO SUL, BRAZIL \\ NATURALLY INFECTED AND NON INFECTED BY Trypanosoma cruzi AND T. \\ evansi
}

Filipe Martins Santos ${ }^{1}$ ORCID - http://orcid.org/0000-0003-2032-8129

Gabriel Carvalho de Macedo ORCID - http://orcid.org/0000-0002-4596-5733

Wanessa Teixeira Gomes Barreto² ORCID - http://orcid.org/0000-0003-2970-1321

Wesley Arruda Gimenes Nantes ${ }^{1 *}$ ORCID - http://orcid.org/0000-0002-3454-4714

William Oliveira de Assis ${ }^{1}$ ORCID - http://orcid.org/0000-0003-3327-0800

Heitor Miraglia Herrera1 ORCID - http://orcid.org/0000-0003-2404-8765

${ }^{1}$ Universidade Católica Dom Bosco, Campo Grande, MS, Brasil.

'Universidade Federal do Mato Grosso do Sul, Campo Grande, MS, Brasil.

*Autor para correspondência - wesley anantes@hotmail.com

\section{Resumo}

O objetivo do trabalho foi avaliar a influência do sexo, da sazonalidade e de infecções por Trypanosoma cruzi e Trypanosoma evansi nos valores hematológicos de lobinhos (Cerdocyon thous) que habitam o Pantanal Sul-Mato-Grossense. Entre novembro de 2015 e outubro de 2016, foram amostrados 48 lobinhos. Os valores hematológicos mensurados foram as contagens de eritrócitos e leucócitos, volume globular e volume corpuscular médio. Consideramos como parasitados os animais positivos para T.cruzi e T. evansi em qualquer um dos testes diagnósticos utilizados. Observamos que sete (14.5\%) lobinhos encontraram-se parasitados somente por T.cruzi, sete por T. evansi, e nove (19\%) estavam coinfectados. Os animais parasitados por T.cruzi mostraram um aumento significativo das contagens de leucócitos $\left(14.7 \times 10^{3}\right)$ em relação aos animais não parasitados $\left(10.4 \times 10^{3}\right)$, parasitados por $T$. evansi $\left(12.4 \times 10^{3}\right)$ e coinfectados $\left(12.9 \times 10^{3}\right)$. Observamos diferença significativa em relação aos valores médios de eritrócitos e volume corpuscular médio entre os períodos de cheia e seca: 2.6 x $10^{6}$ e 165 , e 3.4 x $10^{6}$ e 132 , respectivamente. Todos apresentaram macrocitose não confirmada morfologicamente.

Palavras-chave: lobinho, hematologia, silvestres, Trypanosoma

\begin{abstract}
The aim of this work was to evaluate the influence of sex, seasonality and infections by Trypanosoma cruzi and Trypanosoma evansi on the hematological values of crab-eating foxes (Cerdocyon thous) that inhabit the Pantanal from Mato Grosso do Sul. Between November of 2015 and October of 2016, 48 animals were sampled. The hematological values measured were erythrocyte and leukocyte counts, globular volume and mean corpuscular volume. We considered as parasitized the positive animals for T.cruzi and T. evansi in any of diagnostic tests used. We observed that seven (14.5\%)
\end{abstract}


of the crab-eating foxes were parasitized only by T.cruzi, seven by T. evansi, and nine (19\%) were coinfected. The parasitized animals by T.cruzi showed a significant increase in leukocyte counts (14.7 x 103) compared to non-parasitized animals $\left(10.4 \times 10^{3}\right)$, parasitized by $T$. evansi $\left(12.4 \times 10^{3}\right)$ and coinfected $\left(12.9 \times 10^{3}\right)$. We observed a significant difference in relation to mean erythrocyte and mean corpuscular volume values between wet and dry periods: $2.6 \times 10^{6}$ and 165 , and $3.4 \times 10^{6}$ and 132 , respectively. All presented morphologically unconfirmed macrocytosis.

Keywords: Crab-eating Fox, Hematology, Sylvan, Trypanosoma

Recebido em: 10 de dezembro de 2017

Aceito em: 25 de setembro de 2108

\section{Introdução}

Os lobinhos (Cerdocyon thous) são mamíferos de porte médio pertencentes à ordem Carnivora, família Canidae e subfamília Caninae. São animais de hábitos crepusculares-noturnos e generalistas em relação à sua dieta, alimentando-se de frutos, insetos, crustáceos, pequenos mamíferos, aves, répteis, anfíbios e ovos de diversas espécies. Atuam como dispersores de sementes, tanto de frutas nativas como cultivadas ${ }^{(1-5)}$.

Ainda, vivem isoladamente ou em casais, caçam separadamente, de forma não cooperativa.

São amplamente distribuídos no continente sul-americano (Colômbia, Venezuela, Guiana, Suriname, sudeste da Bolívia, Paraguai, Uruguai, nordeste da Argentina e em quase todos os biomas brasileiros), tendo uma grande capacidade de adaptação em ambientes modificados ${ }^{(6,7)}$. Contudo, a fácil adaptabilidade em ambientes variados promove efeitos negativos para a espécie, principalmente quando o hábitat é compartilhado com seres humanos e animais domésticos, de companhia e de produção. Como resultado desse compartilhamento, diversos parasitas comuns a outras espécies têm sido relatados em lobinhos, como bactérias ${ }^{(8-10)}$, vírus ${ }^{(11-13)}$ e protozoários gastrintestinais e sanguíneos ${ }^{(14-18)}$.

Tanto em ambientes compartilhados por humanos e animais domésticos como nos ambientes naturais, a mensuração de valores hematológicos de animais de vida livre tem sido cada vez mais utilizada como uma ferramenta para a avaliação da saúde. De acordo com Fairbrother e O'loughlin ${ }^{(19)}$, os valores hematológicos são necessários na avaliação de efeitos ambientais, de intoxicações e das doenças infecciosas e parasitárias sobre a condição sanitária desses animais. A contagem de glóbulos brancos pode fornecer informações sobre a resposta imune a um agente infeccioso ou parasitário, ao passo que a série vermelha indica principalmente a presença e o grau de anemia ${ }^{(19)}$.

Alguns grupos de parasitas, como os tripanosomatídeos, podem provocar alterações consideráveis nos parâmetros hematológicos tanto de animais domésticos quanto de animais de vida livre. Alterações na série vermelha e branca já foram descritas em cães e quatis, natural e experimentalmente infectados por Trypanosoma cruzi e Trypanosoma evansi ${ }^{(20-24)}$. Por outro lado, alguns estudos demonstram que fatores ambientais e de manejo podem influenciar os parâmetros hematológicos tanto quanto as infecções parasitárias ${ }^{(25)}$.

O Pantanal é uma grande área úmida de savana continental $\left(147,574 \mathrm{~km}^{2}\right.$ no Brasil), tocando a Bolívia ao norte e o Paraguai ao sul( ${ }^{(26)}$. Caracteriza-se pelo solo arenoso, por uma vegetação em mosaico de floresta semidecídua dispersa e campos inundados sazonalmente, de acordo com as três estações distintas: período seco (agosto a novembro), período cheio (dezembro a março) e período de 
vazante (abril a junho) (27). Com uma densidade populacional humana de $<2$ pessoas por $\mathrm{km}^{2}$, e tendo a pecuária extensiva como principal atividade econômica, o Pantanal abriga uma fauna abundante e densa, a qual inclui também os lobinhos, com uma densidade para o Pantanal de Nhecolândia de 0,24 (planícies inundáveis), 0,41 (floresta) e 0,55 (cerrado) ind $/ \mathrm{km}^{2(28)}$, em censos no período diurno apenas. Outra estimativa para o Pantanal, utilizando áreas de uso obtidas através de radiotelemetria, foi de $0,8 \mathrm{ind} / \mathrm{km}^{2(29)}$.

Apesar dos diversos estudos voltados para a biologia e parasitas que infectam os lobinhos, pouco se sabe sobre a influência de fatores biológicos, ambientais ou parasitários nos parâmetros hematológicos desses animais que habitam o ambiente natural. Deste modo, o objetivo do presente estudo foi avaliar se o sexo, a estação do ano e a infecção por T.cruzi ou T. evansi poderiam influenciar nos resultados hematológicos de lobinhos (C. thous) que habitam o Pantanal Sul-Mato-Grossense.

\section{Materiais e métodos}

O estudo foi realizado na região sul do Pantanal ( $18^{\circ} 59$ ' $15^{\prime}$ ' $\mathrm{S}, 56^{\circ} 37^{\prime}$ ' 03”'O). A área, localizada na região da Nhecolândia, apresenta uma fitofisiologia caracterizada por cordões arenosos de florestas decíduas ou semidecíduas, conhecidas como "cordilheiras" ou "capões" (manchas de floresta cercadas por campos de inundação). As áreas florestadas se caracterizam por porções elevadas do relevo não sujeitas a inundações regulares, entremeadas pela planície de inundação e por lagoas permanentes ou temporárias. O período de amostragem foi de novembro de 2015 a outubro de 2016.

Foram capturados 48 lobinhos em armadilhas do tipo box-trap (90 $\mathrm{cm}$ x $45 \mathrm{~cm}$ x $50 \mathrm{~cm}-$ Equipos Fauna $\left.{ }^{\circledR}\right)$, utilizando-se bacon e sardinha enlatada como iscas. Posteriormente à captura, os animais foram sedados através de injeção intramuscular de cloridrato de tiletamina e cloridrato de zolazepan (Zoletil, Virbac ${ }^{\circledR}$ ), respeitando-se a dose estabelecida para a espécie. De cada animal, foram coletados $4 \mathrm{ml}$ de sangue por meio da venopunção jugular, sendo a amostra sanguínea dividida em duas porções: (i) porção depositada em um tubo de $4 \mathrm{ml}$ (Vacuplast ${ }^{\circledR}$ ) contendo ácido etilenodiamino tetra-acético (EDTA K3) para a realização de análises hematológicas, testes parasitológicos e moleculares; (ii) porção depositada em tubo de $4 \mathrm{ml}$ (Vacuplast ${ }^{\circledR}$ ) sem anticoagulante para a realização de testes sorológicos. Os animais foram monitorados durante a sedação quanto aos parâmetros fisiológicos (frequência cardíaca, frequência respiratória, temperatura retal, reflexos podais, pupilares) e parâmetros clínicos (hidratação, tempo de preenchimento capilar, avaliação de mucosas, presença de lesões e fraturas, condição do pelo, condição dentária). Todos os procedimentos de campo e laboratoriais foram realizados de acordo com licenças concedidas pelo Sistema de Informação e Autorização de Biodiversidade do Instituto Chico Mendes para Conservação da Biodiversidade (ICMBio - 49662-5) e pelo Comitê de Ética para Uso Animal da Universidade Católica Dom Bosco, Campo Grande, MS (CEUA - 19/2015).

Para o diagnóstico parasitológico de T. evansi, foi realizada a técnica do micro-hematócrito (MHCT), descrita por $\mathrm{Woo}^{(30)}$. Para o diagnóstico parasitológico de T.cruzi, foi realizado o hemocultivo (HC) de cerca de $200-400 \mu 1$ de sangue total em meio de cultura bifásico NNN (Neal, Novy, Nicolle) LIT (triptose de infusão de fígado), mais $10 \%$ de soro bovino fetal. As semeaduras foram feitas em duplicata e as culturas incubadas a $27^{\circ} \mathrm{C}$ por 30 dias, sendo monitoradas uma vez por semana.

Para a detecção de IgGs anti-T. evansi e anti-T.cruzi, foram realizadas a reação de imunofluorescência indireta (RIFI) e o ensaio imunoabsorvente enzimático (ELISA, Biomanguinhos, Rio de Janeiro-RJ, Brasil), segundo Rocha et al.(15) e Alves et al.(31), respectivamente. 
O DNA genômico foi extraído a partir de $200 \mu \mathrm{l}$ de sangue total de cada amostra, utilizando-se o QIAamp Blood DNA Mini Kit (Qiagen, Hilden, Alemanha), de acordo com as instruções do fabricante. O DNA total foi diluído com $50 \mu \mathrm{l}$ de tampão de eluição e armazenado a $-20^{\circ} \mathrm{C}$ até a realização dos testes moleculares.

A fim de se detectar o DNA dos protozoários T. evansi e T. cruzi nas amostras sanguíneas dos lobinhos, foi realizada a reação em cadeia da polimerase (PCR), dividida em duas etapas. Inicialmente, todas as 48 amostras foram submetidas à PCR, utilizando-se como alvo uma região variável do gene do $18 \mathrm{~S}$ rRNA da família Trypanosomatidae, de acordo com Smith et al. ${ }^{(32)}$. A partir das amostras positivas, foram realizadas PCRs, utilizando-se como alvos os genes 24S $\alpha$ rRNA (específico para T.cruzi) e uma sequência do DNA satélite (específico para T. evansi), de acordo com Souto e Zingales ${ }^{(33)}$ e Masiga et al. ${ }^{(34)}$, respectivamente. Os primers utilizados estão dispostos na Tabela 1.

Tabela 1. Genes-alvo e primers utilizados para detecção de sequências de DNA da família Trypanosomatidae e das espécies T. cruzi e T. evansi em amostras de sangue de lobinhos (Cerdocyon thous) do Pantanal Sul-Mato-Grossense, capturados entre novembro de 2015 e outubro de 2016

\begin{tabular}{lclll}
\hline Gene-alvo & Especificidade & Primers & Sequência & Amplicon \\
\hline & & TRY927F & 5'-GAAACAAGAAACACGGGAG-3' & \\
18S rRNA & & TRY927R & 5'-CTACTGGGCAGCTTGGA-3' & \multirow{2}{*}{$600 \mathrm{pb}$} \\
& & SSU561F & 5'-TGGGATAACAAAGGAGCA-3' & \\
\multirow{2}{*}{ 24S $\alpha$ rRNA } & T. cruzi & D71 & 5'-AAGGTGCGTCGACAGTGTGG-3' & \multirow{2}{*}{$100 \mathrm{pb}$} \\
& & D72 & 5'-TTTTCAG-AATGGCCGAACAGT-3' & \\
DNA satélite & \multirow{2}{*}{ T. evansi } & TBR1 & 5'-GAATATTAAACAATGCGCAG-3' & \multirow{2}{*}{$164 \mathrm{pb}$} \\
& & TBR2 & 5'-CCACCAGAACACCAACCTGA-3' & \\
\hline
\end{tabular}

Foram determinadas as contagens de eritrócitos e de leucócitos, o volume globular (VG) e o volume corpuscular médio (VCM). As contagens de hemácias e leucócitos foram realizadas em Câmara de Neubauer, enquanto a análise do volume globular foi realizada em microcentrífuga para capilares. O VCM foi calculado dividindo-se o VG pelo número de eritrócitos (apenas a unidade da potência de $10^{6}$ ) e multiplicando-se por 10 .

No presente estudo, um animal foi considerado infectado quando positivo em no mínimo um dos testes diagnósticos utilizados: parasitológico, sorológico e molecular. Foi aplicada uma estatística descritiva (média \pm DP) para obtenção dos parâmetros médios hematológicos. O teste de Shapiro-Wilk foi aplicado aos dados para verificar a distribuição normal. Finalmente, o teste Kruskal-Wallis (KW) foi aplicado para determinar se houve diferença nos valores hematológicos (variável dependente), entre os diferentes grupos de infecção, estações e sexo (variáveis independentes). O Post hoc MannWhitney (MW) teste foi utilizado para avaliar resultados pareados do teste de Kruskal-Wallis. As variáveis foram consideradas estatisticamente significativas quando os valores de $\mathrm{p}$ foram $\leq 0.05$. Todas as análises foram realizadas no programa $\mathrm{R}(35)$.

\section{Resultados}

Dos 48 lobinhos coletados (22 fêmeas e 26 machos), sete apresentaram infecção somente para $T$. evansi, sete somente para T. cruzi e nove coinfectados. Nos testes sorológicos, quatro (8\%) lobinhos foram positivos para T. evansi, $13(27 \%)$ para $T$. cruzi, e três $(6 \%)$ mostraram-se coinfectados. Em 
relação ao teste molecular, 10 (21\%) animais apresentaram positividade para T. evansi, sendo um indivíduo positivo na PCR e na sorologia para T. evansi. Além disso, seis lobinhos positivos na PCR para T. evansi apresentaram IgGs anti-T. cruzi, sendo estes considerados coinfectados (Tabela 2). Não houve positividade em nenhum dos testes parasitológicos (MHCT e HC).

Tabela 2. Número de amostras positivas para testes moleculares e/ou sorológicos realizados para Trypanosoma cruzi e Trypanosoma evansi em lobinhos (Cerdocyon thous) capturados entre novembro de 2015 e outubro de 2016 no Pantanal Sul-MatoGrossense

\begin{tabular}{lccc}
\hline Parasita & PCR & PCR T. evansi e \\
No. (\%) & $\begin{array}{c}\text { Sorologia } \\
\text { No. (\%) }\end{array}$ & $\begin{array}{c}\text { Sorol. T.cruzi } \\
\text { No. (\%) }\end{array}$ \\
\hline $\begin{array}{l}\text { Trypanosoma cruzi } \\
\text { Trypanosoma evansi }\end{array}$ & $10(21)$ & $13(27)$ & \\
Coinfecção & & $04(08)$ & \\
\hline
\end{tabular}

Com relação às análises hematológicas, a média da contagem de hemácias foi de $3.1 \pm 0.9$ (x10\% $\left.\mathrm{mm}^{3}\right)$, a média da contagem global de leucócitos foi de $12.6 \pm 5.1\left(\mathrm{x} 10^{3} / \mathrm{mm}^{3}\right)$, a média do volume globular de 40,3 $\pm 8,6$ (\%) e uma média de VCM de $142 \pm 52.8$ (FL). Nenhuma diferença estatística foi encontrada nos valores médios de hemácias $\left(\mathrm{x} 10^{6} / \mathrm{mm}^{3}\right)-\left(\chi^{2}=0.3187, \mathrm{df}=03, \mathrm{p}>0.05\right), \mathrm{VG}(\%)$ $-\left(\chi^{2}=2.552, \mathrm{df}=03, \mathrm{p}>0.05\right)$ e VCM $(\mathrm{FL})-\left(\chi^{2}=0.5056, \mathrm{df}=03, \mathrm{p}>0.05\right)$ entre lobinhos infectados e não infectados. Entretanto, nossos dados indicam uma leve diminuição desses valores em animais infectados por T. evansi (Tabela 3), embora, segundo os valores médios de referência publicados, não caracterizem anemia ${ }^{(36)}$ ou apenas anemia discreta ${ }^{(37)}$. Além disso, foi observado um aumento significativo nos valores médios de leucócitos $\left(\chi^{2}=6.036\right.$, df $\left.=03, p<0.05\right)$ em animais infectados por T. cruzi (Tabela 3 ).

Tabela 3. Valores hematológicos médios de lobinhos (Cerdocyon thous) não infectados e infectados por Trypanosoma evansi (TE), Trypanosoma cruzi (TC) e coinfectados (TE / TC) na sub-região da Nhecolândia, Pantanal, entre novembro de 2015 e outubro 2016

\begin{tabular}{ccccc}
\hline C. thous & $\begin{array}{c}\text { Não infectados } \\
(\mathrm{n}=25)\end{array}$ & $\begin{array}{c}\text { Positivo TE } \\
(\mathrm{n}=07)\end{array}$ & $\begin{array}{c}\text { Positivo TC } \\
(\mathrm{n}=07)\end{array}$ & $\begin{array}{c}\text { Positivo TE/TC } \\
(\mathrm{n}=09)\end{array}$ \\
\hline HEM & $3,1 \pm 1,3 \mathrm{a}$ & $3 \pm 0,4 \mathrm{a}$ & $3,2 \pm 1 \mathrm{a}$ & $3 \pm 1 \mathrm{a}$ \\
VG & $38,1 \pm 7,9 \mathrm{a}$ & $37,7 \pm 3,7 \mathrm{a}$ & $45,6 \pm 19,3 \mathrm{a}$ & $40 \pm 3,6 \mathrm{a}$ \\
VCM & $143,4 \pm 66,1 \mathrm{a}$ & $127,1 \pm 26,9 \mathrm{a}$ & $154,4 \pm 73,2 \mathrm{a}$ & $144,9 \pm 45,1 \mathrm{a}$ \\
LEU & $10.424 \pm 4.491 \mathrm{a}$ & $12.428 \pm 6.897 \mathrm{a}$ & $14.764 \pm 5.528 \mathrm{~b}$ & $12.905 \pm 3.563 \mathrm{a}$ \\
\hline
\end{tabular}

Letras diferentes indicam significância estatística $(p<0.05)$. HEM: Contagem de Hemácias $\left(\mathrm{x} 10^{6} / \mathrm{mm}^{3}\right)$,

VG: Volume Globular (\%), VCM: Volume Corpuscular Médio (FL) e LEU: Contagem Global de Leucócitos $\left(\mathrm{x} 10^{3} / \mathrm{mm}^{3}\right)$.

Quando categorizamos os animais de acordo com o sexo, observamos que as fêmeas apresentaram valores hematológicos ligeiramente acima dos valores encontrados para machos, porém sem significância $(p>0,05)$ (Tabela 4$)$. Em relação ao período de captura, os animais capturados no período de cheia apresentaram diferença significativa nos valores de hemácias (menores) e VCM (maior) quando comparado ao período de seca $(\mathrm{p}<0,05)$ (Tabela 4). 
Tabela 4. Valores hematológicos de lobinhos (Cerdocyon thous) capturados na subregião da Nhecolândia, Pantanal, entre novembro de 2015 e outubro 2016 em relação às variáveis sexo e estação, sem influência do parasitismo

\begin{tabular}{ccccc}
\hline Sexo & Eritrócitos & Leucócitos & VG & VCM \\
\hline Fêmea & $3.3 \pm 1.4^{\mathrm{a}}$ & $12.5 \pm 5.4^{\mathrm{a}}$ & $41 \pm 14^{\mathrm{a}}$ & $143 \pm 68^{\mathrm{a}}$ \\
Macho & $3.0 \pm 0.9^{\mathrm{a}}$ & $11.2 \pm 4.6^{\mathrm{a}}$ & $39 \pm 3^{\mathrm{a}}$ & $143 \pm 50^{\mathrm{a}}$ \\
\hline Estação & Eritrócitos & Leucócitos & VG & VCM \\
\hline Cheia & $2.6 \pm 0.8^{\mathrm{a}}$ & $11.7 \pm 5.8^{\mathrm{a}}$ & $39 \pm 3^{\mathrm{a}}$ & $165 \pm 51^{\mathrm{a}}$ \\
Seca & $3.4 \pm 1.2^{\mathrm{b}}$ & $11.8 \pm 4.7^{\mathrm{a}}$ & $40 \pm 11^{\mathrm{a}}$ & $132 \pm 59^{\mathrm{b}}$ \\
\hline
\end{tabular}

Letras diferentes indicam significância estatística $(p<0.05)$. HEM: Contagem de Hemácias $\left(\mathrm{x} 10^{6} / \mathrm{mm}^{3}\right)$, VG: Volume Globular (\%), VCM: Volume Corpuscular Médio (FL) e LEU: Contagem Global de Leucócitos $\left(\mathrm{x} 10^{3} / \mathrm{mm}^{3}\right)$.

Nossos resultados indicam que os lobinhos no Pantanal têm contato com T. cruzi e desenvolvem anticorpos, uma vez que foi encontrada apenas positividade no teste sorológico. De fato, as infecções por T. cruzi se caracterizam por curtos períodos iniciais de parasitemias (30 a 40 dias pós-infecção), seguidos pela evasão dos parasitas da circulação ${ }^{(21,38)}$. Por outro lado, a parasitemia patente, expressa pela positividade na PCR observada nos lobinhos parasitados por T. evansi, é esperada devido ao curso da infecção por $T$. evansi se caracterizar por períodos sucessivos de remissão de parasitemia, além da variação antigênica do parasita durante o curso da infecção ${ }^{(39,40)}$. Porém, como não foram registrados sinais clínicos fisiopatogênicos, não se podem caracterizar esses animais como doentes ou não.

Embora nossos resultados não mostrem diferença significativa para as contagens de hemácias, VG e VCM na infecção por T. evansi em lobinhos no Pantanal, diferentes graus de anemia ocasionada por infecção de T. evansi vêm sendo registrados em várias espécies de mamíferos na região ${ }^{(23,41-45)}$. Assim como cães domésticos experimentalmente e naturalmente infectados com $T$. evansi apresentaram anemia, caquexia e o óbito ${ }^{(46,47)}$. Porém, nenhum dos resultados dos lobinhos capturados neste estudo caracterizou anemia, moderada ou acentuada. Embora os cálculos indiquem macrocitose, esta deveria ter sido confirmada nas análises microscópicas, como descrito por Weiss e Wardrop ${ }^{(48)}$.

As análises estatísticas mostraram que os menores valores de hemácias e os maiores valores de VCM nos lobinhos estão diretamente associados ao período da cheia. No entanto, a falta da análise microscópica dos esfregaços sanguíneos não permitiu essa confirmação, principalmente na ausência do valor do Conteúdo de Hemoglobina Corpuscular Média (CHCM), imprescindível na correlação microscópia, para definir a morfologia eritrocitária. Principalmente nesse caso, em que a macrocitose calculada é muito superior aos valores de referências publicados ${ }^{(4,36,37)} \mathrm{e}$ poderiam caracterizar intensa regeneração eritrocitária, ainda que os menores valores eritrocitários indicassem apenas anemia discreta, segundo os valores de referência ${ }^{(31)}$.

Apesar de não termos observado influência do sexo nos índices hematológicos avaliados, outros estudos relacionados a diferenças hematológicas entre machos e fêmeas de lobinhos foram reportados, mostrando que os valores de hemácias para as fêmeas são ligeiramente maiores, igualmente ao encontrado no presente estudo. De fato, Silva et al. ${ }^{(49)}$ encontraram, no Pantanal, valores de hemácias para fêmeas e machos de 3,6 e 2,8 $\left(\times 10^{6} / \mathrm{mm}^{3}\right)$, respectivamente, bem como Mattoso et al. ${ }^{(36)}$, em lobinhos cativos, 4,4 $\left(\times 10^{6} / \mathrm{mm}^{3}\right)$ para fêmeas e 4,3 $\left(\times 10^{6} / \mathrm{mm}^{3}\right)$ para os machos. Esses números mostram que animais que habitam a natureza apresentam valores médios de hemácias bem menores 
que aqueles reportados como referência para cães domésticos ${ }^{(50)}$ e lobinhos cativos ${ }^{(36)}$ ou encontraramse anêmicos e os valores elevados de VCM podem indicar regeneração eritropoiética ou não, mas não foram confirmados pela ausência dos esfregaços sanguíneos.

Além disso, a influência observada no aumento de leucócitos dos lobinhos infectados por $T$. cruzi e coinfectados, comparados aos não infectados, se assemelha a relatos em cães infectados pelo $T$. cruzi $^{(22)}$. Os maiores valores médios da leucometria global nesses animais, quando comparados aos não infectados ou positivos apenas para T. evansi, podem ser consequência da imunossupressão transitória observada durante esses períodos ${ }^{(51,52)}$. De fato, o aumento de leucócitos durante a infecção pelo T. cruzi em mamíferos silvestres vem sendo reportado em condições experimentais e naturais em Thrychomis pachyurus e quatis, respectivamente ${ }^{(53,54)}$.

Embora seja esperado que o parasitismo resulte em uma situação desfavorável ao hospedeiro parasitado, nem sempre isso acontece. De fato, as relações simbióticas não são estáticas, mas dinâmicas no tempo e no espaço ${ }^{(55,56)}$. Dependendo de fatores inerentes ao parasita (quantidade de inoculo, diferentes cepas com diferentes graus de virulência e/ou patogenicidade e coinfecções), ao hospedeiro (idade, sexo, estado nutricional/imunológico, condição reprodutiva e raça) e ao meio (escassez de alimentos, condições climáticas severas, fragmentação/diminuição do hábitat original e aquecimento global), o parasitismo pode não resultar em um dano às condições orgânicas e de homeostase de indivíduos ${ }^{(57)}$.

\section{Conclusão}

O sexo e a infecção por T. evansi não influenciaram nos dados hematológicos de lobinhos do Pantanal. Contudo, observamos que os lobinhos soropositivos para infecção por T. cruzi apresentaram valores maiores na contagem global de leucócitos quando comparados aos não infectados ou positivos apenas para T. evansi. Adicionalmente, observamos que os lobinhos na estação da cheia apresentaram contagem de hemácias menores e VCM elevado, quando comparados com a estação da seca, além de uma macrocitose não confirmada morfologicamente.

\section{Referências}

1. Motta-Junior JC, Lombardi JA, Talamoni SA. Notes on crab-eating fox (Dusicyon thous): Seed dispersal and food habits in southeastern Brazil. Mammalia. 1994; 58(1): 156-159.

2. Beisiegel BM. Contribuição ao estudo da história natural do cachorro do mato, Cerdocyon thous, e do cachorro vinagre, Speothos venaticus [tese]. Instituto de Psicologia: Universidade de São Paulo, São Paulo. 1999.

3. Juarez KM, Marinho-Filho J. Diet, habitat use, and home ranges of sympatric canids in Central Brazil. J. Mammal. 2002; 83(4): 925-933. https://doi.org/10.1644/1545-1542(2002)083<0925:DHUAHR >2.0.CO;2

4. Facure KG, Giaretta AA, Monteiro-Filho ELA. Food habits of the crab-eating fox, Cerdocyon thous, in an altitudinal forest of the Mantiqueira Range, Southeastern Brazil. Mammalia. 2003; 67(4): 503-511. https://doi. org/10.1515/mamm-2003-0404

5. Courtenay O, Maffei L. Crab-eating fox Cerdoyon thous (Linnaeus, 1766). In: Sillero-Zubiri, C, Hoffmann M, Macdonald DW. (Eds.). Canids: foxes, wolves, jackals and dogs. Status survey and conservation action plan. Suíça: IUCN/SCC, 2004. pp. 32-38. 
6. Berta A. Origin, diversification, and zoogeography of South American canidae. Fieldiana, Zoology. 1987; 39: 455-471.

7. Medel RG, Jaksik FM. Ecología de los cánidos suramericanos: una revisión. Rev Chil Hist Nat. 1988; 61: 67-79.

8. Vieira AS, Narduche L, Martins G, Schabib Péres IA, Zimmermann NP, Juliano RS, Pellegrin AO, Lilenbaum W. Detection of wild animals as carriers of Leptospira by PCR in the Pantanal biome, Brazil. Acta Trop. 2016; 163: 87-89. https://doi.org/10.1016/j.actatropica.2016.08.001.

9. De Sousa KCM, Herrera HM, Secato CT, Oliveira ADV, Santos FM, Rocha FL, Barreto WTG, Macedo OGC, De Andrade Pinto PC, Machado RZ, Costa MT, André MR. Occurrence and molecular characterization of hemoplasmas in domestic dogs and wild mammals in a Brazilian wetland. Acta Trop. 2017a; 171: 172-181. https://doi.org/10.1016/j.actatropica.2017.03.030

10. Fontalvo MC, Favacho ARM, Araujo AC, Santos NMD, Oliveira GMB, Aguiar DM, Lemos ERS, Horta MC. Bartonella species pathogenic for humans infect pets, free-ranging wild mammals and their ectoparasites in the Caatinga biome, Northeastern Brazil: a serological and molecular study. Braz J Infect Dis. 2017; 21(3): 290-296. https://doi.org/10.1016/j.bjid.2017.02.002.

11. Monteiro GS, Fleck JD, Kluge M, Rech NK, Soliman MC, Staggemeier R, Rodrigues MT, Barros MP, Heinzelmann LS, Spilki FR. Adenoviruses of canine and human origins in stool samples from free-living pampas foxes (Lycalopex gymnocercus) and crab-eating foxes (Cerdocyon thous) in São Francisco de Paula, Rio dos Sinos basin. Braz. J. Biol. 2015;75(2): 11-16. http://dx.doi.org/10.1590/1519-6984.0313

12. Furtado MM, Hayashi EM, Allendorf SD, Coelho CJ, Jacomo, ATA, Megid J, Ramos Filho JD, Silveira L, Tôrres NM, Ferreira Neto, JS. Exposure of free-ranging wild carnivores and domestic dogs to canine distemper virus and parvovirus in the Cerrado of central Brazil. Ecohealth. 2016; 13(3): 549-557. https://doi.org/10.1007/ s10393-016-1146-4.

13. De Souza DN, Carnieli Jr P, Macedo CL, De Novaes RO, Batista HBCR, Rodrigues AC, Pereira PM, Achkar SM, Vieira LF, Kawai JG. Phylogenetic analysis of rabies virus isolated from canids in North and Northeast Brazil. Arch Virol. 2017; 162(1): 71-77. https://doi.org/10.1007/s00705-016-3079-1

14. Herrera HM, Rocha FL, Lisboa CV, Rademaker V, Mourão GM, Jansen AM. Food web connections and the transmission cycles of Trypanosoma cruzi and Trypanosoma evansi (Kinetoplastida, Trypanosomatidae) in the Pantanal Region, Brazil. Trans R Soc Trop Med Hyg. 2011; 105(7): 380-387. https://doi.org/10.1016/j. trstmh.2011.04.008.

15. Rocha FL, Roque AL, Arrais RC, Santos JP, Lima Vdos S, Xavier SC, Cordeir-Estrela P, D'Andrea PS, Jansen AM. Trypanosoma cruzi TcI and TcII transmission among wild carnivores, small mammals and dogs in a conservation unitand surrounding areas, Brazil. Parasitology. 2013; 140(2): 160-170. https://doi.org/10.1017/ $\underline{\mathrm{S} 0031182012001539 .}$

16. Soares JF, Dall'Agnol B, Costa FB, Krawczak FS, Comerlato AT, Rossato BC, Linck CM, Sigahi EK, Teixeira RH, Sonne L, Hagiwara MK, Gregori F, Vieira MI, Martins JR, Reck J, Labruna MB. Natural infection of the wild canid, Cerdocyon thous, with the piroplasmid Rangelia vitalii in Brazil. Vet Parasitol. 2014; 202(34): 156-163. https://doi.org/10.1016/j.vetpar.2014.02.058.

17. Richini-Pereira VB, Marson PM, Silva RC, Langoni H. Genotyping of Toxoplasma gondii and Sarcocystis spp. in road-killed wild mammals from the Central Western Region of the State of São Paulo, Brazil. Rev Soc Bras Med Trop. 2016; 49(5): 602-607. http://dx.doi.org/10.1590/0037-8682-0270-2016.

18. De Sousa KC, Fernandes MP, Herrera HM, Benevenute JL, Santos FM, Rocha FL, Barreto WGT, Macedo GC, Campos JB, Martins TF, De Andrade Pinto PC, Battesti DB, Piranda EM, Cançado PH, Machado RZ, 
André MR. Molecular detection of Hepatozoon spp. in domestic dogs and wild mammals in southern Pantanal, Brazil with implications in the transmission route. Vet Parasitol. 2017b; 237: 37-46. https://doi.org/10.1016/j. vetpar.2017.02.023.

19. Fairbrother, A.; O'Loughlin, D. Hematological values of the mallard (Anas platyrhynchos) during different reproductive states. J. Wildl. Dis. 1990; 26: 78-82.

20. Herrera HM, Alessi AC, Marques LC, Santana AE, Aquino LP, Menezes RF, Moraes MA, Machado RZ. Experimental Trypanosoma evansi infection in South American coati (Nasua nasua): hematological, biochemical and histopathological changes. Acta Trop. 2002 Mar;81(3):203-10. https://doi.org/10.1016/ $\underline{\text { S0001-706X(01)00204-2 }}$

21. Guedes PM, Veloso VM, Mineo TW, Santiago-Silva J, Crepalde G, Caldas IS, Nascimento MS, Lana M, Chiari E, Galvão LM, Bahia MT. Hematological alterations during experimental canine infection by Trypanosoma cruzi. Rev Bras Parasitol Vet. 2012; 21(2): 151-156. http://dx.doi.org/10.1590/S1984-29612012000200015.

22. Duz ALC, Vieira PMA, Roatt BM, Aguiar-Soares RDO, Cardoso JMO, Oliveira FCB, et al. The TcI and TcII Trypanosoma cruzi experimental infections induce distinct immune responses and cardiac fibrosis in dogs. Mem.Inst. Oswaldo. Cruz. 2014; 109:1005-1013. http://dx.doi.org/10.1590/0074-02760140208

23. Olifiers N, Jansen AM, Herrera HM, Bianchi Rde C, D'Andrea PS, Mourão Gde M, Gompper ME. CoInfection and Wild Animal Health: Effects of Trypanosomatids and Gastrointestinal Parasites on Coatis of the Brazilian Pantanal. PLoS One. 2015. http://doi,org/10.1371/journal.pone.0143997

24. Jaimes-Dueñez J, Triana-Chávez O, Valencia-Hernández A, Sánchez-Arévalo D, Poche-Ceballos A, OrtizÁlvarez J, Mejíaa-Jaramillo AM. Molecular diagnosis and phylogeographic analysis of Trypanosoma evansi in dogs (Canis lupus familiaris) suggest an epidemiological importance of this species in Colombia, Prev Vet Med. 2017; 139: 82-89. https://doi.org/10.1016/j.prevetmed.2017.02.007.

25. Parreira DR, Jansen AM, Abreu UG, Macedo GC, Silva AR, Mazur C, Andrade GB, Herrera HM. Health and epidemiological approaches of Trypanosoma evansi and equine infectious anemia virus in naturally infected horses at southern Pantanal. Acta Trop. 2016. http://doi,org/10.1016/j.actatropica.2016.08.005.

26. Alho CJ. Biodiversity of the Pantanal: response to seasonal flooding regime and to environmental degradation. Braz J Biol. 2008; 68(4): 957-966. http://dx.doi.org/10.1590/S1519-69842008000500005.

27. Rodela LG. Unidades de vegetação e pastagens nativas do Pantanal da Nhecolândia, Mato Grosso do Sul [tese]. São Paulo, Brasil: Universidade de São Paulo, 2006.

28. Desbiez ALJ, Bodmer RE, Tomas WM. Mammalian densities in a neotropical wetland subject to extreme climatic events. Biotropica. 2010; 42(3): 372-378. http://dx.doi.org/10.1111/j.1744-7429.2009.00601.x.

29. Rocha FL. Áreas de uso e seleção de habitats de três espécies de carnívoros de médio porte na fazenda nhumirim e arredores, Pantanal da Nhecolândia, MS [dissertação]. 109p. Universidade Federal do Mato Grosso do Sul, Campo Grande, 2006.

30. Woo PT. The haematocrit centrifuge technique for the diagnosis of African trypanosomiasis. Acta Trop. 1970; 27: 384-386. http://doi.org/10.5169/seals-311731

31. Alves FM, De Lima JS, Rocha FL, Herrera HM, Mourão GM, Jansen AM. Complexity and multifactoriality of Trypanosoma cruzi sylvatic cycle in coatis, Nasua nasua (Procyonidae), and triatomine bugs in the Brazilian Pantanal. Parasit Vectors. 2016; 9(1): 378. https://doi.org/10.1186/s13071-016-1649-4

32- Smith A, Clark P, Averis S, Lymbery AJ, Wayne AF, Morris KD, Thompson RCA. Trypanosomes in a declining species of threatened Australian marsupial, the brush-tailed bettong Bettongia penicillata (Marsupialia: Potoroidae). Parasitology. 2008; 135(11): 1329-1335. https://doi.org/10.1017/S0031182008004824. 
33. Souto RP, Zingales B. Sensitive detection and strain classification of Trypanosoma cruzi by amplification of a ribosomal RNA sequence. Mol Biochem Parasitol. 1993; 62(1): 45-52. https://doi.org/10.1016/0166$\underline{6851(93) 90176-X}$

34. Masiga DK, Smyth AJ, Hayes P, Bromidge TJ, Gibson WC. Sensitive detection of trypanosomes in tsetse flies by DNA amplification. Int J Parasitol. 1992; 22 (7): 909-918. https://doi.org/10.1016/0020-7519(92)90047-O.

35. R Development Core Team [Internet]. R: a language and environment for statistical computing. 2015. Acesso em: 18 de setembro de 2017. Disponível em: http:// www.R-project.org.

36. Mattoso, Cláudio RS., Catenacci, Lilian S, Beier, Suzane L, Lopes, Raimundo S, Takahira, Regina K. Hematologic, serum biochemistry and urinary values for captive Crab-eating Fox (Cerdocyon thous) in São Paulo state, Brazil. Pesqui. Vet. Bras. 2012; 32(6): 5p. 59-566. https://dx.doi.org/10.1590/S0100$\underline{736 \times 2012000600015}$

37. Jorge RSP, Jorge MLSP. Carnivora - Canidae (Cachorro-do-mato, Cachorro-vinagre, Lobo-guará e Raposado-campo). 2014. In: Cubas Z.S., Silva J.C.R. \& Catão-Dias J.L. (Eds). Tratado de Animais Selvagens: Medicina Veterinária. 2.ed. São Paulo: Roca, pp.764-778.

38. Machado EM, Fernandes AJ, Murta SM, Vitor RW, Camilo Jr DJ, Pinheiro SW, Lopes ER, Adad SJ, Romanha AJ, Pinto Dias JC. A study of experimental reinfection by Trypanosoma cruzi in dogs. Am J Trop Med Hyg Title. 2001; 65(6): 958-965. DOI: https://doi.org/10.4269/ajtmh.2001.65.958.

39. Aquino LP, Machado RZ, Alessi AC, Marques LC, De Castro MB, Malheiros EB. Clinical, parasitological and immunological aspects of experimental infection with Trypanosoma evansi in dogs. Mem. do Inst. Oswaldo Cruz. 1999; 94 (2): 255-260. http://dx.doi.org/10.1590/S0074-02761999000200025.

40. Jones TW, McKinnell CD. Antigenic variation in Trypanosoma evansi: variable antigen type development in mice, sheep and goats. Trop Med Parasitol. 1985; 36(3): 53-57.

41. Herrera HM, D'avila AMR, Norek A, Abreu UG, Souza SS, D'Andrea OS, et al. Enzootiology of Trypanosoma evansi in Pantanal, Brazil.Vet. Parasitol. 2004; 125: 263-275. https://doi.org/10.1016/j. vetpar.2004.07.013

42. Silva RAMS, Victórico AM, Ramirez L, Dávila AMR, Trejano V, Jansen AM. Hematological and Blood chemistry alterations in coatis (Nasua nasua) naturally infect by Trypanosoma in the Pantanal, Brazil. Pathologie Parasitaire communication .Rev. Elev. Med. Vet. Pays.Trop. 1999; 52:119-122.

43. Alves FM, Olifiers N, Bianchi RC, Duarte AC, Cotias PMT, D'Andrea PS, et al. Modulating Variables of Trypanosoma cruzi and Trypanosoma evansi transmission in Free-Ranging Coati (Nasua nasua) from the Brazilian Pantanal Region. Vector Borne Zoonotic Dis. 2011; 11: 835-41. https://doi.org/10.1089/ vbz.2010.0096

44. Rademaker V, Herrera HM, Raffel TR, P.S. D'Andrea PS,Freitas TPT, Abreu UGP, Hudson PJ, Jansen AM. What is the role of small rodents in the transmission cycle of Trypanosoma cruzi and Trypanosoma evansi (Kinetoplastida Trypanosomatidae)? A study case in the Brazilian Pantanal, Acta Trop. 2009; 111: 102-107. https://doi.org/10.1016/j.actatropica.2009.02.006.

45. Herrera HM, Abreu UG, Keuroghlian A, Freitas TP, Jansen AM. The role played by sympatric collared peccary (Tayassu tajacu), white-lipped peccary (Tayassu pecari), and feral pig (Sus scrofa) as maintenance hosts for Trypanosoma evansi and Trypanosoma cruzi in a sylvatic area of Brazil. Parasitol Res. 2008; 103: 619-624. https://doi.org/10.1007/s00436-008-1021-5

46. Aquino LPCT, Machado RZ, Alessi AC, Santana AE, Castro MB, Marques LC, et al. Hematological, biochemical and anatomopathological aspects of the experimental infection with Trypanosoma evansi in dogs. 
Arq. Bras. Med. Vet. Zootec. 2002; 54: 8-18. http://dx.doi.org/10.1590/S0102-09352002000100002

47. Reddy BS, Kumari KN, Sivajothi S, Rayulu VC. Haemato-biochemical and thyroxin status in Trypanosoma evansi infected dogs. J. Parasit. Dis. 2014; 40: 491-495. http://dx.doi.org/10.1007/s12639-014-0531-6

48. Weiss DJ,Wardrop KJ. Schalm's veterinary hematology. 6th ed. Iowa: Wiley-Blackwell. 2010. p. 155,156$157,1025,1062$.

49. Silva RAMS, Lima ESS, Sanchez V. Estudos Preliminares sobre os Valores hematológicos do lobinho (Cerdocyon thous) do Pantanal, MS. Embrapa: Circular Técnica, 56, 2004.

50. Feldman, BV, Zinkl, JG, Jain, NC. 1., \& Schalm, O. W. 1. (2000). Schalm's veterinary hematology. 5th ed. Philadelphia: Lippincott Williams \& Wilkins.

51. Pinazo MJ, Espinosa G, Cortes-Lletget C, Posada EdeJ, Aldasoro E, Oliveira I, et al. Immunosuppression and Chagas disease: a management challenge. PLoS Negl. Trop. Dis. 2013; 7:e1965. https://doi.org/10.1371/ journal.pntd.0001965

52. Barr SC, Gossett KA, Klei TR. Clinical, clinic pathologic, and parasitologic observations of trypanosomiasis in dogs infected with North American Trypanosoma cruzi isolates. Am. J. Vet. Res. 1991; 52:954-960.

53. Martínez-Hernández F, López-Díaz O, Bello-Bedoy R, Villalobos G, Munõz-García CI, Alejandre-Aguilar $\mathrm{R}$, et al. Possible Differences in the Effects of Trypanosoma cruzi on Blood Cells and Serum Protein of Two Wildlife Reservoirs. Vector Borne Zoonotic Dis. 2016; 16: 709-716. https://doi.org/10.1089/vbz.2016.1986

54. Roque A, D'Andrea PS, Andrade GB, Jansen AM. Trypanosoma cruzi: distinct patterns of infection in the sibling caviomorph rodent species Thrichomys apereoides laurentius and Thrichomys pachyurus (Rodentia, Echimyidae). Exp. Parasitol. 2005; 111:37-46. https://doi.org/10.1016/j.exppara.2005.05.003

55. Poulin R. Evolutionary ecology of parasites. Princeton: University Press, 2007. 332p.

56. Araújo A, Jansen AM, Bouchet F, Reinhard K, Ferreira LF. 2003. Parasitism, the diversity of life, and paleoparasitology. Mem. Inst. Oswaldo Cruz. 2003; 98(1): 5-11. http://dx.doi.org/10.1590/S0074$\underline{02762003000900003}$

57. Poulin R, Combes C. The concept of virulence: interpretations and implications. Parasitol Today. 1999; 15(12): 474-475. http://dx.doi.org/10.1016/S0169-4758(99)01554-9 